\title{
Caminhos teórico-metodológicos para a investigação de livros escolares: contribuição do Centro de Investigación MANES*
}

GLADYS MARY GHIZONI TEIVE Universidade do Estado de Santa Catarina, Florianópolis, SC, Brasil

RESUMO

Este artigo objetiva analisar os caminhos teórico-metodológicos trilhados pelo Centro de Investigación en Manuales Escolares (MANES), na Espanha. Para tal, privilegia as duas perspectivas que têm embasado as investigações desse centro ao longo de seus vinte anos de existência: a dos "emissores" e a dos "receptores" das mensagens dos textos escolares. Em relação à primeira, são enfatizados os estudos relacionados à análise do conteúdo textual e iconográfico dos livros escolares, a que se convencionou chamar de "tradição de investigação ideológica". Em relação à segunda - a dos receptores -, são destacadas neste artigo as incursões dos pesquisadores do centro pelo chamado "giro contextual", referente tanto ao contexto de produção dos livros escolares quanto ao contexto de seu uso. Destaca-se, ainda, a utilização da metodologia da intertextualidade, consubstanciada no estudo combinado do livro com diferentes fontes provenientes dos contextos de recepção, a qual tem contribuído para o desentranhamento de uma das questões mais difíceis da manualística: a da metodologia do uso dos livros nas salas de aula e a consequente aproximação com a história da cultura escolar.

\section{PALAVRAS-CHAVE}

livros escolares; "giro contextual"; intertextualidade; cultura escolar.

* Este artigo é parte dos resultados do estágio pós-doutoral realizado no Centro de Investigación en Manuales Escolares, de janeiro a setembro de 2013, em Madri, Espanha, o qual teve como interlocutora a professora doutora Gabriela Ossenbach Sauter. 


\title{
THEORETICAL AND METHODOLOGICAL PATHS FOR THE INVESTIGATION OF TEXTBOOKS: THE CONTRIBUTION OF THE CENTRO DE INVESTIGACIÓN MANES
}

\begin{abstract}
This article seeks to analyze theoretical and methodological paths taken by the Centro de Investigación en Manuales Escolares, in Spain. To this end, it emphasises the two perspectives that have been the base of investigations throughout its twenty years of existence: one about "issuers" and another about "receptors" of the messages from textbooks. For the first one, are emphasized the studies related to the analysis of textual and iconographic content of textbooks, the so called "ideological research tradition". For the second one - the receptors -, are highlighted in this article the incursions of the centre's research on the "contextual spin", referring to both, the textbook production context and the context of its use. Also of note, the use of intertextuality methodology, based on the combined study of the book with different sources from the reception contexts, which has contributed to the disemboweling of the most difficult issues of manualistic practice: the methodology of using books in the classroom and the consequent approach to the history of school culture.
\end{abstract}

KEYWORDS

textbooks; "contextual turn"; intertextuality; school culture.

\section{CAMINOS TEÓRICO-METODOLÓGICOS PARA LA INVESTIGACIÓN DE MANUALES ESCOLARES: LA CONTRIBUCIÓN DEL CENTRO DE INVESTIGACIÓN MANES}

\section{RESUMEN}

Este artículo objetiva analizar los caminos teórico-metodológicos trillados por el Centro de Investigación MANES, en España. Para tal, privilegia las dos perspectivas que han fundamentado las investigaciones a lo largo de sus veinte años de existencia: la de los "emisores" y la dos "receptores" de los mensajes de los textos escolares. En relación a la primera perspectiva -que se ha convenido llamar de "tradición de investigación ideológica"- se enfatizan los estudios relacionados al análisis del contexto textual e iconográfico de los manuales escolares. En relación a la segunda -la de los receptores- se destacan en este artículo las incursiones de los investigadores del centro por el llamado "giro contextual", referente tanto al contexto de producción de los manuales escolares cuanto al contexto de su uso. Se destaca, aun, la utilización de la metodología de la intertextualidad, consubstanciada en el estudio combinado del manual con diferentes fuentes provenientes de los contextos de recepción, lo cual ha contribuido al desentrañamiento de una de las cuestiones más difíciles de la manualística: la de la metodología del uso de los manuales en el aula y la consecuente aproximación a la historia de la cultura escolar.

PALABRAS CLAVE

manuales escolares; "giro contextual"; intertextualidad; cultura escolar. 
Durante as últimas três décadas, disseminou-se entre os historiadores da educação um forte interesse pelo funcionamento interno da escola, pela história cotidiana das práticas escolares, a que se convencionou chamar de cultura escolar. Das fontes históricas disponíveis para adentrar o universo das práticas e fazeres escolares, uma das mais profícuas tem sido certamente o conjunto dos livros utilizados nas escolas. Desde a origem dos sistemas nacionais de educação no começo do século XIX, os livros escolares, com seus diferentes formatos, características e conteúdos, ocuparam um lugar privilegiado nas salas de aulas de todos os países.

Sob a égide da chamada pedagogia tradicional, eles dividiram com o mestre o protagonismo da cena escolar. Na pedagogia moderna, contribuíram para a prática do método de ensino intuitivo por meio das séries graduadas e dos manuais de lições de coisas. Na Escola Nova, em sintonia com os postulados da "escola ativa", centrada na atividade do aluno, os livros foram ressignificados, aproximando-se do que Agustín Escolano Benito (2006, p. 330-331) chamou de modelo de livro ativo, "un padrón que ofrecerá una estructura abierta, no predeterminada por el autor, al menos en parte, cuya lectura y implementación requiere siempre la intervención del sujeto".

De modo que, na esteira do que disse Michel Apple (1997), pode-se afirmar que quase $70 \%$ do que faziam os professores e os alunos nas salas de aula nas escolas, até há bem pouco tempo, estava relacionado, de uma ou outra forma, com os livros. $\mathrm{Na}$ chamada sociedade multimedial e do conhecimento, isso certamente mudou, mas não podemos negar que o livro ainda mantenha, ao lado de outras textualidades, seu lugar nas salas de aulas como "mediación pedagógica esencial" (Escolano Benito, 2012, p. 39).

Daí resulta sua indiscutível relevância para a história do currículo e da cultura escolar. Todavia, apesar de ser uma fonte valiosa para o historiador da educação, a pesquisa histórica sobre o livro foi, durante muito tempo, negligenciada, despontando somente a partir do final dos anos 1970. As razões para tal fato, segundo Alain Choppin (2000), um dos primeiros estudiosos da área, estão relacionadas ao próprio status do livro escolar, historicamente considerado como produto de pouco valor cultural. Editados em escala massiva, reeditados e reimpressos à exaustão, os livros escolares eram considerados objetos de consumo e produtos perecíveis. Por conta disso, foram pouco conservados. Dada a sua trivialidade, banalização, abundância e ampla difusão, não despertaram o interesse nem dos profissionais do livro, dos historiadores ou do poder público, seja no que se refere a seu registro, seja no que concerne à sua conservação. Para Choppin (idem, p. 14-15), esse descuido foi de tal monta que os então "abundantes e triviais livros escolares estão hoje ameaçados de extinção, assim como os catálogos das editoras sobre as publicações escolares".

Hoje, cientes de sua importância, os pesquisadores da área são unânimes em admitir que o estudo do livro escolar oferece um amplo leque de possibilidades de pesquisa, o que tem impulsionado a criação de inúmeros centros dedicados à sua investigação, dando origem a um novo campo intelectual no mundo da pesquisa histórico-educativa, batizado pelo historiador espanhol Agustín Escolano Benito de "manualística". O primeiro desses centros foi fundado na Alemanha, em 1975, sob a coordenação do historiador Georg Eckert. Em parceira com a Organização 
das Nações Unidas para a Educação, a Ciência e a Cultura (UNESCO), o Georg-Eckert-Institut für Internationale Schulbuchforschung, com sede em Braunschweig, dedicou-se desde seus primórdios - e ainda se dedica nos dias de hoje - às pesquisas comparativas acerca da autoimagem, da imagem do outro e da imagem do "inimigo" nas sociedades, transmitidas por meio dos textos escolares e de outros meios relevantes na formação escolar. Nesse cenário, disciplinas como história, geografia, ciências sociais e políticas adquirem um significado especial (Mahamud, 2012b). Um dos projetos atuais do instituto, em parceria com a UNESCO, é a investigação, por meio dos livros escolares, sobre como as escolas de todo o mundo lidam com a questão do holocausto.

Em 1980, foi criado em Paris, por iniciativa de Alain Choppin, o Projeto Emmanuelle no Service d'Histoire de l'Éducation, do Institut National de Recherche Pédagogique (INRP), com o objetivo de inventariar e catalogar os manuais escolares utilizados na França a partir da Revolução Francesa até a atualidade. $\mathrm{O}$ trabalho coordenado por Choppin, alicerçado na criação de uma base de dados informatizada e na realização de estudos e publicações, inspirou a criação de outros projetos similares, tal como o Les Manuels Scolaires Québécoises, em 1993, no Canadá; o Proyecto MANES (Manuales Escolares), em 2000, na Espanha; o Projeto EDISCO, que reúne pesquisadores de seis universidades italianas; o LIVRES, banco de dados de livros escolares brasileiros da Universidade de São Paulo (USP); o Programa HISTELEA: História Social do Ensino de Leitura na Argentina; o Centro Internacional de la Cultura Escolar (CEINCE), em 2006, na Espanha, entre outros (Tiana Ferrer, 2010, p. 219).

Foram criadas também, ao longo dos últimos trinta anos, sociedades científicas como a International Association for Research on Textbooks and Educational Media (IARTEM), na Noruega, e a International Society for Historical and Systematic Research on Schollbooks, em Augsburg, na Alemanha. O interesse manifestado pelos livros escolares nas últimas décadas pode ser comprovado também pela organização de exposições, congressos e seminários, bem como por publicações, tal como a Serie Proyecto MANES, da Universidad Nacional de Educación a Distancia (UNED), totalmente dedicada aos manuais escolares. ${ }^{1}$ Nesse sentido, é emblemático o fato de a International Association Standing Conference of the History of Education (ISCHE) ter consagrado o tema "O livro e a educação" a sua XXI Reunião Anual, realizada no ano 2000, em Alcalá de Henares, na Espanha.

\section{O PROYECTO MANES E A INVESTIGAÇÃO SOBRE MANUAIS ESCOLARES}

O Proyecto MANES foi fundado em Madri, na Espanha, no início da década de 1990, por iniciativa do professor Federico Gómez Rodriguez de Castro, do

1 A relação completa das obras publicadas pela coleção Serie Proyecto MANES pode ser conferida em: <http://www.uned.es/manesvirtual/ProyectoManes/Publicaciones.htm>. Acesso em: 29 out. 2013. 
Departamento de Historia de la Educación y Educación Comparada, da UNED. Apesar de ter surgido na UNED, desde seu início contou com a participação de professores das universidades de Valladolid (Agustín Escolano Benito), de Murcia (Antonio Viñao Frago), de Salamanca (José Maria Hernandez Diaz), de Sevilla (Maria Nieves Gómez), de Málaga (Mercedes Vico) e da Complutense (Julio Ruiz Berrio). Ao longo de sua existência, a ele foram se somando investigadores de outras universidades espanholas, europeias e latino-americanas, o que lhe conferiu um caráter interuniversitário e internacional, do qual a Red Patre-Manes (Patrimonio Escolar - Manuales Escolares), ${ }^{2}$ financiada pela União Europeia, representa a concretização mais significativa (Somoza Rodriguez, 2006, p. 2). Em função dessa sua abrangência, no ano de 2003, o Proyecto MANES transformou-se no Centro de Investigación MANES.

\section{O LONGO CAMINHO EM TORNO DOS “EMISSORES DAS MENSAGENS” DOS MANUAIS ESCOLARES}

Em seus primeiros anos, após a realização do censo dos livros utilizados no ensino primário e secundário espanhol, de 1808 até $1990,{ }^{3}$ bem como da legislação e dos planos de estudos que os regularam, ${ }^{4}$ os investigadores do MANES voltaram-se para a análise de seu conteúdo, de modo a "conocer lo qué había dentro de esos libros que se inventariaban y catalogaban" (Ossenbach Sauter, 2012, p. 4). Começam a surgir, então, os primeiros estudos sobre os manuais escolares por nível (primário, secundário e universitário) e por área ou matéria específica do currículo, especialmente os de história, geografia, educação cívica e urbanidade, nos quais são

2 As universidades e instituições que fazem parte da Red Patre Manes são: Universidades Nacionales de Luján y del Nordeste (Argentina); la Universidad del Atlántico (Colombia); o Centro de Investigaciones y Estudios Superiores de Antropología Social (CIESAS) (México); a Universidade de Lisboa (Portugal); as Universidades Católica de Lovaina y Gante (Bélgica) e a Universidad Nacional de Educación a Distancia (UNED) (España). Para maiores informações, consultar a página web de la Red: <http://hum. unne.edu.ar/investigacion/educa/alfa/index.htm>, ou o blogue <http://redpatremanes. blogspot.com/>. Acesso em: 23 abr. 2015.

3 A escolha desse período temporal justifica-se pelo fato de ter sido em princípios do século XIX que se originou a estrutura do sistema educativo espanhol. A partir das Cortes de Cádiz, período em que começaram a ser editadas as normas e as leis que o organizaram e o dividiram em níveis, foram fixados os planos de estudos, estabelecida uma mínima estrutura de financiamento, além da criação da inspeção escolar e da organização da formação de mestres etc. A opção pelo limite temporal superior em 1990 explica-se por ter sido o ano em que foi promulgada a Ley de Ordenación General del Sistema Educativo (LOGSE), que promoveu uma profunda reforma educativa, que afetou não apenas a estrutura do sistema como também os conteúdos curriculares (Somoza Rodriguez, 2006, p. 3).

4 Como produto dessa catalogação, foi criada a Base de Dados MANES. Disponível em: <http://www.uned.es/manesvirtual/portalmanes.html>. Acesso em: 29 out. 2013. 
mais evidentes a carga ideológica e seu impacto na construção de subjetividades e identidades coletivas.

Trata-se de uma tendência bastante consolidada no centro, a que se convencionou chamar de "tradición de investigación ideologica" (Johnsen, 1996, p. 82). A tendência pode ser igualmente constatada no currículo do primeiro curso de doutorado proposto pelo Departamento de Historia de la Educación y Educación Comparada, do qual o MANES faz parte, intitulado "História del curriculum: el libro escolar, reflejo de influencias pedagógicas y intenciones políticas (siglos XIX y XX)"; também faz parte das temáticas dos primeiros congressos organizados pelo projeto, como o de 1996, intitulado "El libro escolar: reflejo de intenciones políticas e influencias pedagógicas", cujos artigos foram publicados em $2000 \mathrm{em}$ obra homônima organizada por Alejandro Tiana Ferrer.

Nessa primeira etapa, os livros produzidos para o ensino primário foram os mais analisados, o que, segundo Tiana Ferrer (2010, p. 214), pode ser explicado pelo fato de que historicamente o controle sobre tais livros na Espanha era bem menos rigoroso do que o dos livros de texto do ensino secundário e universitário, o que resultou na existência de mais de mil títulos aprovados durante o século XIX para uso das escolas primárias. Por conta disso, são abundantes os estudos sobre os manuais de lições de coisas - tanto os dedicados aos alunos quanto aos professores,$-{ }^{5}$ assim como sobre os manuais de leitura, que compendiavam conteúdos disciplinares muito diversos, os quais, em seu conjunto, formavam parte do currículo desse nível de ensino.

De acordo com Guereña, Ossenbach Sauter e Pozo (2005), a revisão da literatura internacional relativa à história dos manuais escolares revela que os livros de leitura são os que mais têm sido estudados. Todavia, as análises, em geral, referem-se mais aos conteúdos ideológicos do que aos estudos da leitura como disciplina escolar, tal como vem realizando o Projeto HISTELEA, da Universidad de Luján, na Argentina, já citado, que se dedica ao estudo específico dos livros escolares da escola primária daquele país. No levantamento realizado por Tiana Ferrer (2010), relativo a esse período, destacam-se as análises do conteúdo de catecismos, manuais de religião e os manuais para meninas, como os de higiene, puericultura e economia doméstica, além dos livros utilizados para a formação de professores, com destaque para a obra Los manuales de pedagogía y la formación del profesorado en las escuelas normales de España (1839-1901), de autoria de Teresa Rabazas Romero, publicada pela Coleção Serie Proyecto MANES, em 2001.

No Brasil, segundo um levantamento realizado por Munakata (2001), apesar da enorme quantidade de livros didáticos produzidos, estes não haviam merecido, até o final do século XX, muita atenção por parte dos pesquisadores. Em sua opinião, as pesquisas até então se concentravam em três modalidades de abordagens; a) no livro didático como apêndice da história do livro em geral; b) nas relações entre organização do texto, tipografia e legibilidade, fixação de conteúdos e aprendizagem; c) no livro didático como instrumento de dominação ideológica e como veículo de

5 Destacam-se, no gênero dos manuais de lições de coisas os estudos pioneiros de Federico Gómez Rodríguez de Castro, fundador do MANES. 
conteúdos insuficientes, incorretos, inadequados ou prejudiciais (idem, p. 336). Tal como nos primeiros anos do MANES, observa-se no Brasil uma forte tendência relativamente ao último aspecto, cenário que vem sendo alterado a partir das pesquisas pioneiras de Circe Maria Fernandes Bittencourt, Kátia Abud e Maria Auxiliadora Schmidt sobre os livros e manuais didáticos de história; de Eliane Peres, sobre os de pedagogia e didática; de Denice Barbara Catani e Cynthia Pereira de Sousa, sobre as revistas pedagógicas do magistério; de Marta Chagas de Carvalho, sobre os saberes pedagógicos; de Diana Gonçalves Vidal, sobre as práticas de leitura e escrita na escola pública primária no final do século XIX; de Heloisa Helena Pimenta Rocha, sobre os manuais de higiene; de Maria Teresa Santos Cunha e Maria Stephanou, sobre manuais de civilidades; de Ana Crhystina Mignot, Anabela Almeida Costa e Santos, Márcia de Paula Gregório Razzini, Kazumi Munakata, entre outros. ${ }^{6}$

O censo realizado no início da década de 1990 sobre os manuais escolares, além dos da legislação e dos planos de estudos em vigor no período de 1808 a 1990, possibilitou aos investigadores do MANES cotejar uns e outros com o contexto social e econômico em que eram produzidos. Nesse sentido, merecem destaque as pesquisas acerca da política seguida na Espanha e sua relação com os manuais escolares, publicadas na coleção dirigida por Agustín Escolano Benito (1997,1998), sobre a história do livro na Espanha, do Antigo Regime à Segunda República e do pós-guerra à reforma educativa. Também permitiram situar no contexto socioeconômico as pesquisas de José Luiz Villalain Benito $(1997,1999,2002)$ acerca das disposições legais espanholas sobre os manuais escolares, publicadas em três volumes, que ensejam aos interessados múltiplas análises no campo da política do livro escolar, das relações entre o Estado e as editoras, dos manuais proibidos e dos autorizados, das redes de influência, enfim, sobre como se estruturou e evoluiu a paisagem editorial escolar espanhola, entre muitas outras frentes (Tiana Ferrer, 2010, p. 220).

Ainda na linha de investigação política e legislativa, cabe destacar as pesquisas relativas ao controle dos livros de texto em diferentes períodos históricos e as que analisam os conflitos ideológicos surgidos em torno da seleção de livros escolares e sobre os momentos da história espanhola em que se tentou impor textos únicos como na ditadura de Primo de Rivera, ou no primeiro franquismo. Somam-se a estas, ainda, as investigações sobre a produção e comercialização de livros de texto e sobre a história das editoras e de seus editores no período da transição democrática (idem, p.222). A partir dos anos 2000, observa-se, no MANES, o florescimento de pesquisas que abordam a investigação dos manuais em relação aos estudos sobre as mulheres e sua educação, desde os que as tomam como autoras, mestras ou usuárias dos

6 A criação, em 1994, na Faculdade de Educação da Universidade de São Paulo, de um banco de dados de livros escolares produzidos no Brasil (LIVRES) tem contribuído para alavancar as pesquisas na área dos manuais escolares, por disponibilizar livros didáticos produzidos no Brasil desde o século XIX aos dias atuais, bem como legislação, programas curriculares, catálogos de editoras e bibliografia de pesquisas nacionais e internacionais sobre o tema. Sobre o LIVRES, conferir: <www2.fe.usp.br:8080/livres/\#>. Acesso em: 29 nov. 2013. 
manuais, aos que as focam como destinatárias, além dos dedicados às análises dos livros de texto como transmissores de modelos sobre homens e mulheres e a relação entre ambos os gêneros.

Nesse mesmo período, além da análise do conteúdo textual dos manuais das áreas das ciências humanas e sociais, foram surgindo investigações sobre os livros de ciências naturais, como a de José María González Clouté sobre o imaginário social da radioatividade e da energia nuclear nos manuais espanhóis de física e de química durante a segunda metade do século XX (González Clouté, 2011); e a de Margarida Hernandéz Laille, sobre o Darwinismo y manuales escolares en España e Inglaterra en el siglo XIX (1870-1902), na qual são discutidas as resistências e os atrasos na apropriação dos avanços científicos na cultura da escola (Hernandéz Laille, 2010). Foi também no início do século XXI que os conteúdos iconográficos dos manuais passaram a ser objeto de interesse dos investigadores do MANES. Suas análises seguiram, regra geral, a tônica das análises textuais realizadas pelo centro, focadas no seu papel de instrumentos a serviço da construção da identidade nacional e do doutrinamento ideológico; nas identidades de gênero e de etnia; na urbanidade e na formação religiosa. Destacam-se, nessa área, as pesquisas de Badanelli Rubio (2003, 2007, 2008b). Nesse período, o aspecto que mais parece ter atraído a atenção dos investigadores continuou sendo, certamente, a função de transmissão de valores e de ideologias que os manuais desempenham e o papel que cumprem enquanto instrumentos de socialização política.

Essas e outras pesquisas desenvolvidas no MANES demonstram a vitalidade da análise de conteúdo textual e iconográfico dos manuais escolares no que se refere à sua contribuição no campo da manualística, do currículo e da política educacional. $\mathrm{Na}$ Espanha, especificamente, essa é uma questão particularmente importante, haja vista que, em determinados momentos de sua história, o livro cumpriu a função do currículo oficial. Daí a importância crescente que os estudos foram adquirindo sobre as editoras, sobre o mercado de livros e suas exigências, sobre a mediação que os editores faziam com os autores das obras e vice-versa e, consequentemente, sobre o estudo dos autores dos livros, seu perfil, de onde eram, quais suas relações com os editores, qual seu papel na sociedade etc. Questões, como bem advertiu Roger Chartier, que devem ser incorporadas ao conceito de "sociologia do texto":

contra la abstracción del texto, enseña que el status e interpretación de un trabajo depende de consideraciones materiales; contra "la muerte del autor", pone el acento en el rol del autor, ubicando este al lado del impresor/vendedor a la hora de definir la forma dada al trabajo; contra la ausencia del lector, recuerda que el significado de un texto siempre se produce en un contexto histórico y depende de las lecturas diferentes y plurales que le asignan un significado. (apud Guereña; Ossenbach Sauter; Pozo, 2005, p. 22)

Diante da relevância desses estudos, os pesquisadores do MANES são unânimes em afirmar que as pesquisas na área da manualística precisam avançar para além de mostras muito pequenas de livros escolares, muitas vezes de um só livro, ou de livros de editoras de pouca difusão tomados como fonte, ou, ainda, estudos 
que não levam em conta critérios mínimos para selecionar mostras representativas de acordo com alguns critérios básicos, como número de edições, relevância e grau de difusão das editoras, seu caráter regional etc., o que pode gerar resultados irrelevantes para a investigação ou conclusões que camuflam o impacto de um manual em um momento ou circunstâncias determinadas (Ossenbach Sauter, 2012, p. 5).

\section{“UM TEXTO É O QUE OS SEUS LEITORES FAZEM DELE” - ${ }^{7}$ APROXIMAÇÕES AO “CONTEXTO DE RECEPÇÃO” DOS MANUAIS ESCOLARES}

No workshop Italo-Español sobre a "Historia de la cultura escolar", organizado pelo MANES, pelo CEINCE e pela Università Degli Studi de Macerata, Itália, em novembro de 2011, Gabriela Ossenbach Sauter, atual diretora do MANES, teceu considerações críticas sobre os caminhos percorridos pelos MANES ao longo de seus vinte anos de existência. Com o sugestivo título “¿Está agotada la investigación sobre manuales escolares?”, faz uma interessante provocação aos investigadores da área, com o intuito de impulsionar o debate. O principal sintoma e/ou indício desse esgotamento, em sua opinião, estaria no fato de algumas linhas de investigação empreendidas no campo da manualística terem exaurido suas possibilidades de contribuir, a partir do campo da história, para uma teoria sobre a cultura escolar, ou seja, para "la comprensión de los procesos de enseñanza y aprendizaje en el aula $\mathrm{y}$ de las tradiciones y regularidades sedimentadas a lo largo del tiempo en la práctica de las escuelas" (idem, p. 7).

Nessa perspectiva, em sua avaliação, o foco dado pelo Centro de Investigación MANES à análise dos "emissores das mensagens" dos livros, seja no que se refere ao currículo prescrito pelas políticas e legislação, seja pelo currículo apresentado aos professores, ${ }^{8}$ não estaria contribuindo para o avanço das investigações no campo da história da cultura escolar, área que mobiliza muitos de seus pesquisadores a partir dos anos 2000. Segundo Ossenbach Sauter, portanto, o grande dilema para o MANES e a manualística hoje é o fato de que se, em parte, os livros de texto têm sido uma valiosa fonte de conhecimentos para a história do currículo escolar, eles, por si sós, dificilmente poderão proporcionar ao historiador da educação informações acerca da complexa história da prática nas salas de aula, das mediações e transformações realizadas pelos professores sobre o material do livros de texto e, para efeito da compreensão da cultura produzida pelas escolas, sobre como as mensagens veiculadas nas salas de aula foram recebidas e decodificadas pelos alunos (idem, p. 8).

$7 \quad$ Frase de Umberto Eco (1999, p. 79).

8 Utilizamos aqui a classificação do pedagogo espanhol José Gimeno Sacristán para os agentes moldadores do currículo: 1) currículo prescrito; 2) currículo apresentado aos professores; 3 ) currículo modelado pelos professores; 4) currículo em ação; 5) currículo realizado; 6) currículo avaliado (Sacristán, 2010, p. 127-403). 
Claro está, para o grupo MANES, a complexidade exigida pela tarefa de acercar-se do uso dos manuais nas salas de aula. Como pondera Ossenbach Sauter (idem, p. 7),

no es fácil encontrar evidencias de la forma en la que se han utilizado los textos escolares en las aulas y, de otra parte, es preciso indagar sobre las formas de apropriación de los discursos y prácticas contenidos en los textos escolares por parte de los sujetos que aprenden.

Parafraseando Chartier (apud Ossenbach Sauter, 2012, p. 7), completa:

La cuestión esencial que debe plantear toda la historia del libro, de la edición $\mathrm{y}$ de la lectura es la del proceso mediante el cual los lectores, espectadores $\mathrm{u}$ oyentes dan sentido a los textos de los que se aproprian.

Em busca de vestígios ou evidências de como os "receptores das mensagens", professores ou alunos, recebem, trabalham e decodificam as mensagens dos textos escolares, os pesquisadores do MANES vêm percorrendo, nos últimos anos, novos caminhos teóricos e metodológicos. Entre os primeiros, merecem destaque as incursões pela história cultural, história do currículo, etno-história, etnografia, cultura escolar, história de vida e das instituições escolares, etc. No que diz respeito aos caminhos metodológicos, destacamos o chamado "giro contextual", que se relaciona com a variedade de marcos de referência que dão sentido aos textos escolares. $\mathrm{O}$ contexto, nessa perspectiva, refere-se tanto ao âmbito escolar quanto ao extraescolar, ou seja, o "giro contextual", na área da manualística, estaria relacionado tanto ao contexto de produção dos manuais escolares quanto ao de seu uso ou recepção, uma questão muito bem sintetizada na afirmação de Antonio Viñao Frago (2006, p. 29): "Todo el texto remite a varios contextos: los de produción y incorporación de sentidos, los de recepción y interpretación”.

Em sintonia com os últimos estudos na área da manualística, as pesquisas de âmbito intraescolar desenvolvidas no MANES enfatizam a necessidade de contextualização do manual escolar dentro de suas variadas áreas, combinando-as com outras fontes primárias complementares, incorporando nas análises o estudo das produções infantis. Foi esse o caminho metodológico seguido por Kira Mahamud Angulo, em sua tese de doutoramento, intitulada Adoctrinamiento emocional y socialización política en el primer franquismo (1939-1959). Emociones y sentimientos en los manuales escolares de enseñanza primaria, agraciada, em 2012, com o Prêmio Extraordinário de Doctorado. ${ }^{9}$ Analisando os livros escolares como projetos didáticos, Mahamud os dividiu em suas diferentes partes, seções ou microtextos: as introduções e/ou apresentações do autor e/ou editor, o corpus instructivo, as atividades, os epílogos e os índices. A cada um/a deles/as deu um tratamento de textualidade diferenciado, enfatizando a linguagem figurativa como técnica de ensino. Isso lhe permitiu indagar mais a fundo os discursos presentes nos diferentes

9 Prêmio concedido pelo Vicerrectorado de Investigación de la UNED. 
textos, bem como comprovar a associação ou não entre os microtextos entre si e entre eles e os contextos (social e do ensino primário) da época estudada.

Partindo do pressuposto de que a "la expresión de una epoca también puede ser definida por su linguaje” (Mahamud, 2012a, p. 52), lançou mão da análise dos estilos de narração linguística e das características estilísticas das mensagens, da linguagem figurativa, das metáforas etc., presentes nos textos escolares, conseguindo avançar sobremaneira na compreensão do quanto e de que modo os manuais escolares refletem, projetam, transmitem ou não o que é legitimado na sociedade e as formas utilizadas para tal. Nessa perspectiva, pôde comprovar que "os silêncios também são bem reveladores”, como advertiu Alain Choppin (2002, p. 20).

Quanto à metodologia do entrecruzamento de diferentes fontes primárias, as pesquisas sobre a cultura escolar na ditadura franquista a partir dos cadernos escolares e das imagens de gênero e da infância realizadas por Maria del Mar del Pozo Andrés (Universidad de Alcalá de Henares) e Sara Ramos Zamora (Universidad Complutense de Madrid), as de Antonio Castillo Gómez e de Veronica Sierra Blas (Universidad de Alcalá de Henares), sobre a história da cultura escrita e os usos cotidianos da escrita nos séculos XIX e XX, as de Antonio Viñao Frago sobre os aspectos metodológicos e historiográficos das pesquisas com cadernos e exames escolares, e as de Ana Maria Badanelli Rubio e de Kira Mahamud Angulo (UNED) têm revelado grandes avanços relativamente ao momento e às condições de recepção das mensagens dos textos por parte de professores e alunos. Complementares ao estudo do manual, as fontes primárias provenientes dos contextos de recepção, como exames, folhas de exercícios, diários de mestres e de alunos, informes de inspeção, atas de reuniões pedagógicas e diferentes tipos de cadernos escolares podem auxiliar o pesquisador a detectar, em primeiro lugar, quais livros foram efetivamente utilizados pelos professores nas classes. Essa é uma questão importante relativamente ao estudo sobre como o professor e a escola em geral reagem diante do currículo a eles apresentado. Em segundo lugar, permitem uma maior aproximação do uso e do consumo que deles se fizeram e, consequentemente, da cultura escolar.

Em suas pesquisas, a partir de uma coleção de cadernos escolares do período do pós-guerra espanhol, obtidos por doação, Mahamud e Badanelli Rubio (2011) vislumbraram as interessantes possibilidades que essas fontes podem oferecer no campo da manualística e da cultura escolar. Tal como os manuais escolares, os cadernos também são fontes documentais de intenções educativas, mas estão inquestionavelmente mais próximos da etnografia da escola, como argumenta Ossenbach Sauter (2012, p. 9). Por meio da análise de suportes das escritas infantis e da linguagem escrita escolar, o pesquisador pode aproximar-se um pouco mais das práticas das salas de aula, haja vista que se constituem em testemunhos do que foi realizado por professores e alunos, das experiências dirigidas e compartilhadas.

Para a análise de sua coleção de cadernos, Kira Mahamud e Ana Maria Badanelli Rubio desenvolveram uma metodologia específica que pode ser explicada em quatro etapas: 1) o caderno como objeto de estudo; 2) a marca dos manuais nos cadernos; 3) a diversificação na investigação: conteúdos específicos e primeiros estudos comparados; 4) a renovação metodológica. 
A primeira etapa diz respeito ao conhecimento das características internas e externas dos cadernos. Nela, os cadernos são "radiografados", buscando respostas para questões tais como: quem, para que e por que se usa o caderno. Nessa fase, inicia-se uma primeira aproximação ao estudo das matérias, dos conteúdos, exercícios de aplicação e desenhos que ilustram suas páginas e, ainda, das anotações das mestras (Badanelli Rubio; Mahamud, 2008; Mahamud; Badanelli Rubio, 2011). $\mathrm{Na}$ segunda etapa, realiza-se o cotejo dos cadernos com os manuais escolares, com o objetivo de buscar suas marcas nas atividades tradicionais do dia a dia das classes, como cópias de textos e/ou de ilustrações, ditados, redações, exercícios etc. Esse caminho metodológico permite aproximações significativas sobre o uso do manual na sala de aula, para saber se as cópias eram fiéis aos textos e às ilustrações dos livros ou se continham pequenas alterações e/ou grandes bricolagens; se os ditados eram provenientes de um ou vários textos; se as redações davam margem a interpretações próprias dos textos dos livros pelos alunos; se havia redações livres, etc. (Badanelli Rubio; Mahamud, 2008; Mahamud; Badanelli Rubio, 2011).

$\mathrm{Na}$ terceira etapa é então realizado o estudo independente dos conteúdos selecionados pelo pesquisador. No caso de Kira Mahamud, são selecionados os conteúdos emocionais; no de Ana Maria Badanelli Rubio, os conteúdos sobre a religião católica, e inicia-se a investigação comparativa entre diferentes tipos de cadernos (de rotação ou de classe, ${ }^{10}$ de deveres e caderno individual), buscando evidenciar a forma como os conteúdos e as atividades são apresentados nos vários cadernos; a distribuição do espaço; a apresentação; a estética e as ilustrações. Nessa fase, podem-se comparar também o trabalho docente das professoras e o trabalho dos alunos, como produção e mostra de rendimento escolar. As atividades realizadas nas aulas e o trabalho dos professores refletem-se nos cadernos dos alunos por meio de suas anotações, instruções e correções, o que, na avaliação de Mahamud e Badanelli Rubio (2011, p. 15), confirma que os mestres "forman parte de la autoria del documento escolar", o que pode permitir ao pesquisador uma maior aproximação ao modelo de docência, que é o modo como os professores organizam as tarefas que os alunos devem realizar, como as corrigem e controlam seus trabalhos em geral (Mahamud, 2008, 2010; Badanelli Rubio,2008a, 2010; Mahamud; Badanelli Rubio, 2011).

$\mathrm{Na}$ última etapa, são combinadas as fontes escritas com as fontes orais, por meio de entrevistas com os autores dos cadernos e com seus professores. Nessa fase, apesar dos problemas que o trabalho com a memória e com as emoções e sentimentos envolve, podem-se preencher vazios deixados pelas fontes escritas, obtendo-se ricas informações sobre como se trabalhava no caderno, o grau de orientação e liberdade de expressão do aluno, até que ponto o caderno refletia o que havia sido estudado em classe por meio do manual, qual a frequência de revisão dos cadernos

10 De acordo com Mahamud e Badanelli (2011, p. 6), os cadernos de "rotação", "circulação" ou de "classe" são aqueles em que participam todos os alunos da classe. A cada dia, um deles se encarrega de realizar algumas atividades práticas, as quais, regra geral, são selecionadas entre as lições do dia. 
por parte dos professores, qual a participação dos pais no seu acompanhamento etc. (Mahamud; Badanelli Rubio, 2011; Mahamud, 2012a).

Ainda sobre o estudo combinado do manual com outras fontes primárias complementares, os/as pesquisadores/as do MANES destacam a análise dos exames escolares. Os exames fazem parte do que José Gimeno Sacristán (2010) chamou de "currículo avaliado", por ser o suporte pelo qual se avalia o que foi prescrito em termos de educação escolar. Não é sem razão, portanto, que os exames têm grande importância, seja para os responsáveis pelas políticas públicas, seja para os dirigentes escolares, pais, professores e alunos. Infelizmente, pouco explorados nas investigações na área da história do currículo, da cultura escolar e da manualística - talvez pela dificuldade de encontrá-los, tal como os cadernos -, os exames podem oferecer uma preciosa contribuição ao historiador da educação, uma vez que possibilita avançar "un paso a más" no que diz respeito à recepção das mensagens que os manuais transmitem (Mahamud; Badanelli Rubio, 2011, p. 4). Deles podem ser extraídos dados sobre que manuais foram utilizados e, destes, os conteúdos considerados mais válidos e relevantes. Oferecem também informações sobre as concepções de ensino-aprendizagem em vigor pela maneira como são elaboradas as questões, a maneira de respondê-las e como são corrigidas, tal como advertem Viñao Frago (2001) e Díaz Barriga (1994).

Quanto ao contexto extraescolar, ainda na perspectiva do "giro contextual", observam-se significativos avanços metodológicos no MANES. Além das fontes, também são pesquisadas as legislações que regeram a elaboração dos manuais, as políticas que os inspiraram e o contexto social e econômico em que foram produzidos. Tais legislações têm sido incluídas na literatura e se continuam sendo contempladas. Também foram incluídos outros, como a literatura, as autobiografias, os relatos sobre a vida cotidiana, os jornais e as revistas da época e os discursos sobre a educação escolar que circulavam em revistas pedagógicas e em manuais de formação de professores, os quais poderiam, de alguma forma, ter influenciado os autores dos manuais escolares. A incorporação dessas novas fontes às tradicionais, no que se refere ao contexto extraescolar, objetivam auxiliar o historiador a reconstruir o "clima da época" - ao que Mahamud chamou de "clima emocional", influenciada pelos recentes estudos da área do affective turn ou "giro emocional", teoria que utilizou para analisar o grau de associação ou dissociação entre os sentimentos e as emoções que prevaleceram na sociedade do pós-guerra espanhol e os encontrados nos manuais adotados na escola primária da época (Mahamud, 2012a).

Em síntese, é por intermédio de uma metodologia contextualizada e interdocumental e, portanto, mediante a produção de uma rica intertextualidade, que se tenta, no MANES, aproximar-se da história da prática da sala de aula - a cultura escolar -, essa "misteriosa chama" que, para Catteew, Dams, Depaepe e Simon (2005), constitui a caixa-preta da história da educação ainda por decifrar.

Nesse sentido, o caminho seguido pelos pesquisadores do Centro de Investigación MANES em muito se assemelha ao percorrido por Giambattista Bodoni, personagem de La misteriosa llama de la Loana (A misteriosa chama da rainha Loana), de Umberto Eco. Após sofrer um acidente vascular cerebral, Bodoni, um livreiro de meia-idade, perde a memória pessoal, a mais ligada às emoções, e é aconselhado por 
seu médico a passar uma temporada na casa de campo da família, onde viveu sua infância. No porão da velha casa, dedica-se a cotejar seus livros e cadernos escolares com os materiais típicos da cultura de massas da Itália dos anos 1940: discos, recortes de jornais, revistas, gibis, cartazes de filmes, canções populares e hinos fascistas. A leitura atenta de seus antigos cadernos escolares, sobretudo das cópias, ditados e redações, repletos de frases históricas de Mussolini, fê-lo enveredar pelos diferentes contextos da produção e incorporação desses sentidos. Essa intertextualidade possibilitou-lhe reconstruir a identidade de sua geração e do momento cultural vivido pelo país no período da Segunda Guerra Mundial.

O chamado "giro contextual", intra e extraescolar, alicerçado no entrecruzamento das fontes primárias complementares às do livro escolar que vem sendo experimentado no MANES e em outros centros de investigação sobre manuais escolares, não implicou o abandono das análises de conteúdo, como os de viés ideológico; ao contrário, propõe a aproximação entre estas e os estudos voltados ao interior da escola, aos estudos da cultura escolar, sem os quais é praticamente impossível resolver uma das questões mais polêmicas da manualística: a da metodologia do uso dos livros escolares nas salas de aula.

\section{REFERÊNCIAS}

Apple, M. Maestros y textos: una economía política de relaciones de clase y sexo en educación. Barcelona: Paidós, 1997.

Badanelli Rubio, A. M. Ilustraciones en los manuales escolares (España 1900-1970). 2003. Tese (Doctorado) - Facultad de Educación, Universidad Nacional de Educación a Distancia (UNED), Madrid, 2003.

.El uso de las imágenes en la enseñanza de la religión durante el franquismo. In: Congreso Iberoamericano de Historia de la Educación Latinoamericana, 8., 2007, Buenos Aires. Anais... Buenos Aires, 2007, p. 1-21. (Contactos, cruces y luchas en la historia de la educación latinoamericana)

A estética e as ilustrações nos cadernos escolares: o caso de uma escola de meninas na Espanha franquista. In: Мignot, A. C. V. (Org.). Cadernos à vista. Escola, memória e cultura escrita. Rio de Janeiro: EDUERJ, 2008a. p. 239-255.

. Ser español en imagenes: la construcción de la identidad nacional a través de las ilustraciones de los textos escolares (1940-1960). Historia de la Educación. Revista Interuniversitaria, Salamanca: Universidad de Salamanca, n. 27, p. 137-169, $2008 \mathrm{~b}$.

Cuadernos de rotación, cuadernos de deberes: un estúdio comparado.In: MedA, J.; Montino, D.; Sani, R. (Eds.). School exercise books. A complex source for a history of the approach to schooling and education in the 19 and 20 centuries. Florencia: Polistampa, 2010. v. 2, p. 793-802.

.; Mahamud, K. Cuadernos escolares. Un ejemplo de la práctica de la escritura escolar en el franquismo. In: Castillo Goméz, A.; Sierra Blas, V. (Eds.). Mis primeiros pasos. Alfabetizacion, escuela y usos cotidianos de la escritura (siglos XIX y XX). Gijón: Editorial Trea, 2008. p. 259-279. 
Catteew, K.; Dams, K.; Depaepe, M; Simon, F. Filming the black box: primary schools on film in Belgium: a first assessment on unused sources. In: Mietzner, U.; Myers, K.; Peim, N. (Orgs.). Visual history. Images of education. Oxford: Peter Lang, 2005. p. 203-231.

Choppin, A. Los manuales escolares de ayer y hoy. El ejemplo de Francia. Historia de la Educación. Revista Interuniversitaria, Salamanca: Universidad de Salamanca, n. 19, p. 13-37, 2000.

. Os historiadores e o livro escolar. História da Educação, Pelotas: ASPHE/ UFPEL, n. 11, p. 5-24, 2002.

Díaz Barriga, Á. Una polémica en relación al examen. Revista Iberoamericana de Educación, OEI, n. 5, p. 161-181, mayo/ago. 1994. Disponível em: <http://www.rieoei. org/olivirt/rie05a05.pdf>. Acesso em: 13 out. 2013.

Eco, U. Lector in fabula: la cooperación interpretativa en el texto narrativo. Barcelona: Lumen, 1999.

La misteriosa llama de la reina Loana. España: Debolsillo, 2011.

Escolano Benito, A. Historia ilustrada del libro escolar en España. Del Antiguo Régimen a la Segunda República. Madrid: Fundación Germán Sánchez Ruipérez, 1997.

Historia ilustrada del libro escolar en España. De la postguerra a la reforma educativa. Madrid: Fundación Germán Sánchez Ruipérez, 1998.

. La recepción de los modelos de la Escuela Nueva en la manualistica en comienzos del siglo XX. Historia de la Educación, Revista Interuniversitaria, Salamanca: Universidad de Salamanca, n. 25, p. 317-340, 2006.

O manual como texto. In: Rocha, H. H. P.; Somoza Rodrigues, M. (Orgs.). Dossiê: manuais escolares: múltiplas facetas de um objeto cultural. Pro-Posiçôes, Campinas: UNICAMP, v. 23, n. 3, p. 33-50, set./dez. 2012.

GonzÁlez Clouté, J. M. El imaginario social de la radioactividad y la energía nuclear en los manuales de fisica y quimica durante la segunda mitad del siglo XX. 2011. Tesis (Doctorado en Historia de la Educación) - Facultad de Educación, Universidad Nacional de Educación a Distancia, Madrid, 2011.

Guereña, J.-L.; Ossenbach Sauter, G.; Pozo, M. M. (Eds.). Manuales escolares en España, Portugal y América Latina (siglos XIX y XX). Madrid: MANES/UNED, 2005.

Hernandéz Laille, M. Darwinismo y manuales escolares en España e Inglaterra en el siglo XX (1870-1902). Madrid: MANES/UNED, 2010.

Johnsen, E. B. Libros de texto en el caleidoscopio. Estudio crítico de la literatura y la investigación sobre los textos escolares. Barcelona: Pomares Corredor, 1996.

Mahamud, K. O conteúdo emocional de três cadernos escolares do franquismo. In: Mignot, A. C. V. (Org.). Cadernos à vista. Escola, memória e cultura escrita. Rio de Janeiro: EDUERJ, 2008. p. 205-221.

. Labor docente y trabajo escolar bajo el catolicismo franquista (1945-1959). In: Meda, J.; Montino, D.; SAni, R. (Eds.). School exercise books. A complex source 
for a history of the approach to schooling and education in the 19 and 20 centuries. Florencia: Polistampa, 2010. v. 2, p. 747-767.

Adoctrinamiento emocional y socialización politica en el primer franquismo (1939-1959).

Emociones y sentimientos en los manuales escolares de enseñanza primaria. 2012. Tesis (Doctorado) - Facultad de Educación, Universidad Nacional de Educación a Distancia, Madrid, 2012a.

. Estancia de investigación pós-doctoral de Kira Mahamud en el Georg Eckert Institut fur Internationale Schulbuchforschung. Braunschwelg, Alemania: UNED, 2012b. Disponível em: <http://portal.uned.es>. Acesso em: 25 out. 2010.

.; Badanelli Rubio, A. M. La producción escolar como objeto de estudio. Una aproximación a los avances metodológicos en manualística. 2011. Mimeografado. $18 \mathrm{p}$.

Munakata, K. Brasil. In: Ossenbach Sauter, G.; Somoza Rodriguez, M. Los manuales escolares como fuente para la historia de la educación en América Latina. Madrid: UNED, 2001. p. 337-344.

Ossenbach Sauter, G. ¿̇ Esta agotada la investigación histórica sobre manuales escolares? Consideraciones criticas sobre la investigación en el campo de la manualistica, a 20 años de la fundación del Centro de Investigacion MANES. 2012. Mimeografado. $11 \mathrm{p}$.

.; Somoza Rodriguez, M.(Eds.) Los manuales escolares como fuente para la historia de la educación en América Latina. Madrid: UNED, 2001.

Rabazas Romero, T. Los manuales de pedagogía y la formación del profesorado en las escuelas normales de España (1839-1901). Madrid: UNED, 2001.

SACRIstán, J. G. El curriculum: una reflexión sobre la practica. Madrid: Morata, 2010. Somoza Rodriguez, M. El "Proyecto MANES" y la investigación sobre manuales escolares: uno balance critico de resultados y nuevos desafios. History of Education E Childhood, Florencia: Universitad de Macerta, n. 1, p. 1-17, 2006.

Tiana Ferrer, A. (Org.) El libro escolar: reflejo de intenciones políticas e influencias pedagógicas. Madrid: MANES/UNED, 2000.

Los manuales escolares. In: Guerena, J.-L.; Ruiz Berrio, J.; Tiana Ferrer, A. (Coords.). Nuevas miradas historiográficas sobre la educación en la España de los siglos XIX y XX. Madrid: Ministerio de la Educación, 2010. p. 209-230.

Villalain Benito,J.L. Manuales escolares en España. Legislación (1812-1939). Madrid: MANES/UNED, 1997. Tomo I.

.Manuales escolares en España. Libros de texto autorizados y censurados (1833-1874). Madrid: MANES/UNED, 1999. Tomo II.

Manuales escolares en España. Libros de texto autorizados y censurados (1874-1939). Madrid: MANES/UNED, 2002. Tomo III.

VIÑAo Frago, A. Escuela graduada de exámenes de promoción: ¿Necesidad endógena o imposición exógena? In: Coloquio Nacional de Historia de la Educación, 11., 2001. Oviedo: Universidad de Oviedo/Sociedad Española de Historia de la Educación, 2001. p. 193-213. 
Los cuadernos escolares como fuente histórica: aspectos metodológicos e historiográficos. Annali di Storia dell'Educazione e delle Istituzione Scolastiche, Castellanza: ESSPER, n.13, p. 17-35, 2006.

\section{SOBRE A AUTORA}

Gladys Mary Ghizoni Teive é doutora em educação pela Universidade Federal do Paraná (UFPR). Professora associada da Universidade do Estado de Santa Catarina (UDESC).

E-mail: gladysteive@gmail.com

Recebido em novembro de 2013 Aprovado em julbo de 2014 